\title{
Physical and emotional well-being and the balance of needed and received emotional support: Age differences in a daily diary study
}

\author{
Julia K. Wolff ${ }^{\mathrm{a}, \mathrm{b}, *}$, Florian Schmiedek ${ }^{\mathrm{a}, \mathrm{c}}$, Annette Brose ${ }^{\mathrm{a}}$, Ulman Lindenberger ${ }^{\mathrm{a}}$ \\ ${ }^{a}$ Max Planck Institute for Human Development, Berlin, Germany \\ ${ }^{\mathrm{b}}$ German Centre of Gerontology, Berlin, Germany \\ ${ }^{\mathrm{c}}$ German Institute for International Educational Research (DIPF), Frankfurt/Main, Germany
}

\section{A R T I C L E I N F O}

\section{Article history:}

Available online 10 May 2013

\section{Keywords:}

Received support

Support needs

Support balance

Daily relationship

Aging

Well-being

\begin{abstract}
A B S T R A C T
Whether received social support matches the actual needs of the recipient is a largely overlooked aspect in research on associations of support and well-being. In particular, studies that investigate the match of needed and received support from a within-person perspective are rare. Therefore, we investigated the daily within-person relationship of well-being and the balance of needed and received social support in a German Sample of 79 younger (23-34 years) and 88 older adults (68-83 years). Health complaints and negative affect were predicted with linear effects of received and needed emotional support and quadratic effects of the balance (i.e., difference) of these two aspects using multilevel modeling of selfreports over 20 days. The predicted beneficial association between a match of needed and received support (i.e., a support balance) and well-being was observed among younger adults. Needed support was associated with more health complaints and negative affect on the same day. The match of needed and received support is important for well-being, particularly in younger adults. Future research should account for support needed in research on received support and shed more light into the processes underlying these short-term within-person relationships of social support and well-being.
\end{abstract}

() 2013 Elsevier Ltd. All rights reserved.

\section{Introduction}

The relationship between social support and physical or emotional well-being has been studied intensively in psychological, medical, and sociological research. Most studies found beneficial effects of the perceived availability of social support on (a) various health measures, for example subjective health, or physical functioning (Cohen, 1988; House, Landis, \& Umberson, 1988; House, Landis, \& Umberson, 2003; Seeman, 2001; Uchino, 2006; Uchino, Cacioppo, \& Kiecolt-Glaser, 1996) and (b) well-being outcomes, for example mood, or life satisfaction (Atienza, Collins, \& King, 2001; Karademas, 2006; Murrell, Norris, \& Chipley, 1992). However, actually received support is sometimes associated with less positive psychological and health outcomes (Krause, 1997; Reinhardt, Boerner, \& Horowitz, 2006). Received and perceived support are only moderately correlated (Haber, Cohen, Lucas, \& Baltes, 2007). Perceived support may be rather a trait of a person

\footnotetext{
* Corresponding author. German Centre of Gerontology, Manfred-vonRichthofen-Str. 2, 12101 Berlin, Germany. Tel.: +49 30 26074034; fax: +49 30 7854350.

E-mail address: julia.wolff@dza.de (J.K. Wolff).
}

than a reflection of past received support (cf. Uchino, 2009). The current study contributes to the explanation of negative effects of received support by investigating the daily association between a balance of needed and received emotional support and health complaints as well as negative affect.

\section{Explanations for adverse effects of received support}

In the literature, there are different attempts to explain negative effects of received support (Seidman, Shrout, \& Bolger, 2006). Receiving support can be a consequence of a lower physical or emotional well-being (i.e., receiving support when feeling bad). Also, both lower well-being and receiving support may relate to a common cause such as a critical life event. Additionally, receiving support can point to deficits and thereby be detrimental for wellbeing as well as self-esteem. With simulated data Seidman et al. (2006) showed that the first two scenarios are very unlikely to cause the negative effects of received support found in the literature. Therefore, received support more likely evokes negative consequences by pointing to deficits or overprotection which may be especially true, when it exceeds the needs of the recipient.

Moreover, empirical evidence suggests that receiving support is not always detrimental: First, an exchange of support (i.e., 
reciprocity in social relationships) was shown to be beneficial for well-being and health, while especially receiving more than giving was associated with less positive outcomes (e.g., Gleason, Iida, Bolger, \& Shrout, 2003; Jung, 1997; Väänänen, Buunk, Kivimaki, Pentti, \& Vahtera, 2005). Second, receiving support from a partner seems beneficial in daily relationships, but only if the support is not noticed by the recipient (Bolger \& Amarel, 2007; Bolger, Zuckerman, \& Kessler, 2000; Gleason, Bolger, Iida, \& Shrout, 2008; Maisel \& Gable, 2009; Shrout, Herman, \& Bolger, 2006).

What has received little attention so far is the importance of a match of needed and received support-in particular, whether received support was actually needed by the recipient in daily life, and this aspect may be crucial to evaluate effects of received support (Cutrona, 1990). The kind and amount of support received should match the individual needs caused by stressful situations (matching hypothesis).

First empirical findings are mainly in accordance with these notions: Over a course of five years, marriage satisfaction was more likely to decline when there was an over- or under-provision of support by the partner (Brock \& Lawrence, 2009). Likewise, receiving less support than requested was related to poorer mental and physical health in a Japanese student sample (Jou \& Fukada, 2002). Conversely, unwanted but received support (including mismatches in kind and amount of support) was associated with poor psychosocial adjustment in women recovering from breast cancer (Reynolds \& Perrin, 2004). In the same vein, a German sample of younger, middle-aged, and older adults rated the occurrence of unwanted support as unpleasant (Smith \& Goodnow, 1999). To our knowledge, only one study did not find negative effects of an oversupply of support on negative affect and perceived stress in a German sample of students (Siewert, Antoniw, Kubiak, \& Weber, 2011). Taken together, both undersupply and oversupply of support may be related to worse health and well-being outcomes.

These effects of a balance of received and needed support are related to and should be discriminated from other concepts of support. While reciprocity is a balance of giving and taking between individuals, the balance of needs and receipts is an evaluation within one individual. Moreover, needing support may be, but is not necessarily, equivalent with seeking support, as a person in need may not become active. Similarly, the provision of support is not verified by the partner who may (or may not) agree that $s /$ he has actually provided it. This means that the balance of received and needed support is a personal evaluation of needs and receipts. It does not include evaluations of the interactive partner (e.g., his or her responsiveness to needs of support; cf. Maisel \& Gable, 2009).

The question of the association between a balance of support and well-being can be approached from two levels: first, as already done in previous work, one can look at between-person relationships, asking questions like: Do persons who in general receive too much or too little support, report lower levels of well-being or a worse health status? Another approach is the within-person perspective asking questions like: Is an over- or undersupply of support on a particular day related to worse well-being or more health complaints on that same day in comparison to days where supply and needs are balanced? Although the congruence between needed and received support may be especially salient at the within-person level, this has not been studied explicitly yet. For example, coping with newly occurring stressors may induce an immediate need for support requiring assistance on the same day. The kind and amount of support received should match the individual needs to cope adequately with the situation. An undersupply of support could indicate unsuccessful coping or ineffective asking for support. Moreover, it may function as a stressor in itself, or it may amplify the negative effect of the source of needed support. Hence, individuals with too little support may report lower physical or emotional well-being. An oversupply of support can also function as a stressor. It can signal unwanted support that the receiver potentially feels obliged to acknowledge, even though it was not helpful. Over and above, an attribution of support need (i.e., overprotection) may give rise to health concerns. That is, support oversupply may encourage the support receiver to dwell on negative feelings and complaints, and hence lower his or her physical and emotional well-being. In summary, those individuals who get as much support as they need on a given day should feel balanced and socially well embedded on that day.

As a consequence of these considerations, we introduce a balance score of received and needed support on a daily basis, that is, a score representing optimal support that is tailored to current needs. We predict that this score shows a quadratic relationship to health and well-being outcomes. As illustrated in Fig. 1, both the oversupply and the undersupply of support may be associated with lower health status or well-being on a given day.

\section{Adult age differences}

As stressors and developmental tasks change across the lifespan, the association between support and well-being is likely to differ between age groups. Even though some studies investigated the relationship between received support and health in older adults (e.g., Krause, 1997; Reinhardt et al., 2006), only one study investigated age differences in effects of unasked-for support. This study revealed that situations with unasked-for support were reported less frequently by older as compared to younger and middle-aged adults (Smith \& Goodnow, 1999). However, the questions were asked retrospectively, and the authors did not assess the difference between needed and received support directly in their daily lives.

More generally, social support may play a crucial role in older adulthood because old age is characterized by losses in several domains such as health and cognitive functioning (Baltes, 1987). Referring to the support-efficacy model (Antonucci \& Jackson, 1987), available support should increase a sense of self-efficacy and thereby enhance well-being, a suggestion that was empirically supported in older adults (self-efficacy beliefs were positively associated with the availability of social relationships; Lang, Featherman, and Nesselroade, 1997). However, as noted earlier, received support is a different matter. On the one hand, received support could help individuals in maintaining relatively high levels

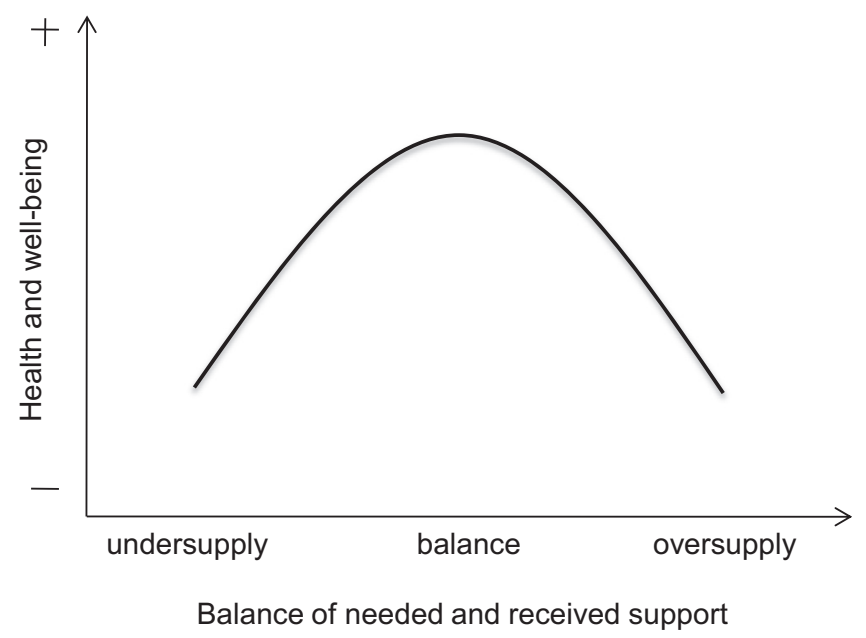

Fig. 1. Illustration of the proposed relationship between balance support and health or well-being. 
of everyday competence. In this case, an undersupply of support leaves an older person alone with his or her problems resulting in worse physical well-being. On the other hand, received support may point to the more prevalent existing deficits and thereby lower self-esteem and well-being of older adults. Here, an oversupply of support may amplify these effects, giving the older person a feeling of dependence and a higher awareness of health problems resulting in worse physical well-being. Thus, oversupply and undersupply of support may both signal a threat to physical well-being, especially for older adults. As almost every person in the older segment of the population suffers from one or more diagnosed health problem (Aldwin, Park, \& Spiro, 2007), health complaints may be taken more serious and health per se may be more important to older than to younger adults. Thus, we predict that the effects of under- and oversupply on health complaints are less pronounced in younger than in older adulthood.

For emotional well-being, the situation may be different. According to socio-emotional selectivity theory, older adults are more likely than younger adults to select social interactions in ways that enhance emotional well-being (Carstensen, 1995; Carstensen, Fung, \& Charles, 2003). Older adults also report higher relationship satisfaction and seem to engage in strategies to maximize positive social experiences (Luong, Charles, \& Fingerman, 2011). Perhaps, then, an oversupply of emotional support may actually enhance well-being among older adults because of high relationship quality with the provider of support. In this case, the negative association between support and well-being would be restricted to undersupply of support in older adults. In contrast, younger adults are faced with different developmental goals. According to Havighurst's developmental tasks (1948), they strive for autonomy, or building up their own households and social networks. For them, an oversupply of support might be a threat to these goals and have adverse effects on health and well-being.

\section{The present study}

In sum, receiving social support is sometimes associated with lower levels of health and well-being. So far, studies on the balance of received and actually needed support in daily experiences on a within-person level are rare. In the present study, we investigated daily associations of needed emotional support, received emotional support, and support balance to self-reported health complaints and negative affect, one important facet of well-being, in younger and older adults. For received and needed support, we expected, consistent with previous research, higher levels of health complaints and negative affect on days when individuals received and needed more support. For support balance, we expected negative effects of both undersupply and oversupply in both age groups. Due to a lack of previous studies, our expectations concerning age group differences were largely explorative. Based on our considerations, we tentatively predicted that effects of support imbalance would be more pronounced for older adults in relation to health, reflecting their greater sensitivity to this domain and less pronounced in relation to negative affect because of the striving for positive emotional experiences in older adulthood.

\section{Method}

This study is part of a larger study, the COGITO Study, which primarily aims at investigating intraindividual variability in cognitive functioning and was conducted at the Max Planck Institute for Human Development in Berlin, Germany. To this end, the participants went through ten days of pretesting, a microlongitudinal phase of on average 101 days, followed by ten days of posttesting from 2006 to 2008 (see Brose, Schmiedek, Lövdén, \&
Lindenberger, 2010; Brose, Schmiedek, Lövdén, \& Lindenberger, 2011; Schmiedek, Bauer, Lövdén, Brose, \& Lindenberger, 2010; Schmiedek, Lövdén, \& Lindenberger, 2009; Schmiedek, Lövdén, \& Lindenberger, 2010). Two years later, participants were invited to come back for a follow-up study. Of the original sample, $81 \%$ underwent another ten days of posttesting, ten daily sessions, and finally one last posttest session. The current study focuses on data from a daily questionnaire of the follow-up study on the ten posttesting and ten daily assessments. The age group comparisons in this study are based on cross-sectional analyses. Ethical approval was given by the ethical review board of the Max Planck Institute for Human Development, Berlin, Germany.

\section{Participants and procedure}

The sample consisted of 79 younger adults (49\% female; $23-34$ years) and 88 older adults (51\% female; $68-83$ years). The ten posttest and ten daily sessions were completed in about four weeks. Participants could complete their sessions daily from Monday to Saturday. The average lag between sessions was 1.6 days.

At the beginning of each session, participants filled in a questionnaire about their well-being, health status, social support, and other measures. Subsequently, they worked on different cognitive tasks. A final questionnaire assessed satisfaction with performance and motivation. The cognitive tasks of posttest and daily sessions differed in content. In the posttest sessions (about $2 \mathrm{~h}$ ) participants worked on different questionnaires and cognitive tasks each day. The daily sessions (about $1 \mathrm{~h}$ ) consisted of a cognitive task battery (perceptual speed, episodic memory, and working memory) that was repeated each day (for details see Schmiedek, Lövdén, et al., 2010). Participants were offered an incentive of $320 €$ (approximately \$425) for completing the study.

The sample in this study may be selective in terms of health. Ninety-two percent of the older adults and $53 \%$ of the younger adults had been participating in the Socio-Economic Panel (SOEP), a representative household panel in Germany (Wagner, Frick, \& Schupp, 2007). Comparisons between the COGITO participants and their age peers among the SOEP participants living in Berlin on selfrated health (SRH) and the number of doctor visits in the past three months revealed that the older COGITO adults rated themselves as healthier, but reported a similar number of doctor visits (SRH: $M(S D)_{\text {SOEP }}=3.33(0.92), M(S D)_{\text {COGITO }}=2.61(1.03), t=5.37, p<0.0001$, Effect Size $d=-0.85$; doctor visits: $M(S D)_{\text {SOEP }}=3.94(4.45)$, $M(S D)_{\text {CоGIто }}=3.26(3.54), t=1.15, p=0.25$, Effect Size $\left.d=-0.16\right)$. The same pattern emerged for the younger adults, but due to the low participation rate, these results should be regarded with caution $\left(\mathrm{SRH}: M(S D)_{\text {SOEP }}=2.31(0.84), M(S D)_{\text {COGITO }}=1.98(0.90), t=2.14\right.$, $p=0.03$, Effect Size $d=-0.39$; doctor visits: $M(S D)_{\text {SOEP }}=3.08(2.63)$, $M(S D)_{\text {COGITO }}=2.74(4.40), t=0.58, p=0.56$, Effect Size $\left.d=0.13\right)$.

\section{Measures}

Daily subjective health status was assessed with a list of different complaints, including items from the Giessen Subjective Complaints List (i.e., headaches and limb aches, gastrointestinal complaints, cardiovascular complaints, and exhaustion; Brähler, Hinz, \& Scheer, 2008), as well as upper respiratory complaints, symptoms of restlessness, and muscle tension. Participants were asked whether they were experiencing one of these complaints and rated them on a 4-point Likert scale with 0 (no, not at all) to 3 (yes, very much). Wolff et al. (2012) showed that five of these complaints form a one-factor solution on an average within-person level, allowing to build one summary score of the complaints for each person in within-person analysis. Therefore, the sum of the ratings 
of the health complaints headaches and limb aches, cardiovascular complaints, exhaustion, upper respiratory complaints, and symptoms of restlessness was included as the dependent variable health complaints in this analysis.

Daily negative affect was assessed with eight items derived from the Positive and Negative Affect Schedule (PANAS; Watson, Clark, \& Tellegen, 1988). Participants rated how well the adjectives distressed, upset, hostile, jittery, ashamed, nervous, irritable, and afraid described their momentary mood on a 8-point scale from 0 (does not apply at all) to 7 (applies very well). Two items from the PANAS, namely guilty and scared, were excluded in the follow-up assessment because they showed little or no intraindividual variance in the first phase of the study. The eight items were averaged to obtain one negative affect score.

Daily received and needed emotional support were assessed with the items "How much emotional support did you receive today?" and "How much emotional support did you need today?" Participants rated them on a 5-point scale with 0 (none) to 4 (very much). As the rating scales were shown above each other on the same screen, participants could report over- and undersupply of support by comparing their answers immediately without being explicitly asked. The balance score was calculated by subtracting the amount of needed support from received support on each day. Thus, positive values indicate an oversupply of support and negative values an undersupply. A complete balance of support equals the value of zero.

Daily perceived stress was included as control variable in our analyses. It was assessed with 6 items on an 8-point scale from 0 (does not apply at all) to 7 (applies very well). Items were adapted from the Perceived Stress Scale by Cohen, Kamarck, \& Mermelstein (1983) and the Daily Inventory of Stressful Events by Almeida, Wethington, \& Kessler (2002).

\section{Data analysis}

To account for the hierarchical structure of the data and to capture day-to-day associations, the data were analyzed with multilevel models using SAS PROC MIXED. Two levels of analysis were included, with level-one being the number of days completed by the participants. Participants' stable individual characteristics, in turn, represent level-two. Two sets of models were computed, one with daily health complaints, and the other with daily negative affect as the dependent variable. An autoregressive parameter accounting for the uneven spacing of the days (with the SPATIAL POWER covariance function in the REPEATED statement of SAS PROC MIXED) was included in all models. A linear trend for the dependent variable was estimated. Predictors on level-one were the time-varying variables received, needed, and balance support and the control variable perceived stress. They were centered around the individual means. To account for individual differences in intraindividual variability, the centered variables were divided by the intraindividual standard deviations for each individual. Estimating the models without dividing the variables by the individual standard deviations did not change the pattern of results. On level-two, age group and the individual means of the time-varying variables were added as predictors. In all analyses, values of $p<0.05$ are interpreted as significant.

Altogether, for each dependent variable (health complaints, negative affect), three multilevel models were estimated: one for each of the predictors, namely support received, needed, and its balance. The following equation was used for received and needed support, with the individual means of the time-varying variables denoted as mean. The predictor variable Session accounts for a potential linear change across study time:
Table 1

Means and intraindividual standard deviations of health complaints, negative affect, and the social support measures.

\begin{tabular}{|c|c|c|c|c|c|c|}
\hline \multirow[t]{2}{*}{ Variable } & \multicolumn{2}{|c|}{ Younger adults } & \multicolumn{2}{|c|}{ Older adults } & \multirow[t]{2}{*}{$p$} & \multirow[t]{2}{*}{ Cohen's $d$} \\
\hline & $M$ & $S D$ & $M$ & $S D$ & & \\
\hline \multicolumn{7}{|l|}{ Mean level } \\
\hline $\begin{array}{l}\text { Needed emotional } \\
\text { support }\end{array}$ & 1.31 & 0.82 & 1.01 & 0.77 & 0.02 & 0.38 \\
\hline $\begin{array}{l}\text { Received emotional } \\
\text { support }\end{array}$ & 1.39 & 0.86 & 1.36 & 0.95 & 0.83 & 0.03 \\
\hline $\begin{array}{l}\text { Balance emotional } \\
\text { support }\end{array}$ & 0.07 & 0.88 & 0.36 & 0.86 & 0.03 & -0.33 \\
\hline Negative affect & 1.41 & 0.92 & 0.49 & 0.61 & $<0.0001$ & 1.21 \\
\hline $\begin{array}{l}\text { Sum of health } \\
\text { complaints }\end{array}$ & 1.53 & 1.17 & 1.46 & 1.63 & 0.75 & 0.05 \\
\hline \multicolumn{7}{|c|}{ Mean intraindividual standard deviation (ISD) } \\
\hline $\begin{array}{l}\text { Needed emotional } \\
\text { support }\end{array}$ & 0.80 & 0.31 & 0.63 & 0.33 & 0.001 & 0.53 \\
\hline $\begin{array}{l}\text { Received emotional } \\
\text { support }\end{array}$ & 0.87 & 0.30 & 0.72 & 0.34 & 0.003 & 0.47 \\
\hline $\begin{array}{l}\text { Balance emotional } \\
\text { support }\end{array}$ & 0.88 & 0.37 & 0.78 & 0.37 & 0.08 & 0.27 \\
\hline Negative affect & 0.64 & 0.29 & 0.31 & 0.24 & $<0.0001$ & 1.25 \\
\hline $\begin{array}{l}\text { Sum of health } \\
\text { complaints }\end{array}$ & 1.29 & 0.7 & 0.9 & 0.58 & 0.0001 & 0.61 \\
\hline
\end{tabular}

$$
\begin{aligned}
\text { Dependentvariable }_{\mathrm{ij}}= & \beta_{0}+\beta_{1}\left(\operatorname{Session}_{\mathrm{ij}}\right)+\beta_{2}\left(\text { AgeGroup }_{i}\right) \\
& +\beta_{3}\left(\text { Support.mean }_{i}\right)+\beta_{4}\left(\text { Support }_{\mathrm{ij}}\right) \\
& +\beta_{5}\left(\text { Support }_{\mathrm{ij}} \times \text { AgeGroup }_{\mathrm{i}}\right)+u_{o i} \\
& +u_{1 i}\left(\operatorname{Sesssion}_{\mathrm{ij}}\right)+u_{2 i}\left(\text { Support }_{\mathrm{ij}}\right)+r_{i j}
\end{aligned}
$$

Reported health complaints and negative affect, respectively, of a person $i$ on occasion $j$ is predicted by the following fixed effects: the intercept $\beta_{0}$, the linear trend $\beta_{1}$, the age group ( 0 younger adults; $1=$ older adults) $\beta_{2}$, the individual mean of received or needed support $\beta_{3}$, the needed or received support of person $i$ on occasion $j$ $\beta_{4}$, the interaction of a person's needed or received support on occasion $j$ with age group $\beta_{5}$. A significant interaction of needed or received support and age group would indicate age group differences in the main effects. The following random effects are included in the equation to account for potential interindividual differences in parameters: the person's deviation from the average level of the dependent variable $u_{0 i}$, the person's deviation from the average linear trend $u_{1 i}$, the person's deviation from the average main effect of needed or received support $u_{2 i}$, and $r_{i j}$ as the person $i$ 's deviation from the individual level of the dependent variable at occasion $j$.

The equation of the model including the balance of received and needed support as predictor was comparable to Equation (1), with Balance_mean $_{\mathrm{i}}$ and Balance $\mathrm{Bij}_{\mathrm{ij}}$ instead of Support_mean $\mathrm{n}_{\mathrm{i}}$ and Support $_{\mathrm{ij}}$, and with the additional predictor Balance ${ }_{i j}^{2}$ (as well as the corresponding random effects and interactions with age group). ${ }^{1}$

In all models, likelihood ratio tests were used to determine whether random effects of support were significant. Random coefficients were assumed to be normally distributed with a mean of zero and variances represented by $\sigma_{u}^{2}$ and $\sigma_{r}^{2}$, and all random effects were allowed to covary. For the sake of clarity, the control variables daily perceived stress and mean perceived stress are not reported in the equation and the result tables.

\footnotetext{
1 To test whether the quadratic effect is either driven only by received or needed support, we also estimated the models with the balance score controlling for either received or needed support. Results were robust for negative affect as well as health complaints as outcomes.
} 


\section{Results}

\section{Descriptive statistics}

Table 1 shows the means and intraindividual standard deviations of all variables, separately for the two age groups. Older adults reported significantly less needed emotional support and lower negative affect. Younger adults had a significantly lower balance support: On average the older adults received more support than needed, while younger adults' balance score was almost zero. Older adults fluctuated significantly less from day to day in received and needed emotional support, negative affect, and health complaints.

\section{Received and needed support}

In Table 2 the estimates of the multilevel models with received and needed emotional support as predictors are shown separately for the dependent variables health complaints and negative affect. We predicted main effects of received and needed support, indicating that the more support needed or received the more health complaints and negative affect are reported.

Health complaints as the dependent variable

There was no reliable effect of received support on health complaints $(\beta=0.05, F(1,3134)=2.08, p=0.15)$. In accordance with our assumptions, the predicted main effect of needed support was positive and significant, indicating that on days with more support needed, more health complaints were reported $(\beta=0.19$, $F(1,3134)=17.54, p<0.0001)$. Needed emotional support accounted for $7 \%$ of the within-person variance of the health complaints. None of the interactions with age group were significant.

\section{Negative affect as the dependent variable}

Received support did not significantly predict negative affect $(\beta=-0.02, F(1,3134)=1.44, p=0.23)$. Yet, the main effect of needed support was reliable $(\beta=0.16, F(1,3134)=79.98$, $p<0.0001)$. Additionally, there was a significant interaction of needed support and age group $(\beta=-0.13, F(1,3134)=30.24$, $p<0.0001)$. Age group accounted for $26 \%$ of the slope variance of needed support. In separate analyses for the age groups, the relationship between needed support and negative affect was significant in both age groups, but stronger for younger adults than for older adults. In younger adults, $11 \%$ and, in older adults, $2 \%$ of the within-person variance of negative affect was accounted for by needed support $\left(\beta_{\text {old }}=0.04, F(1,1669)=15.64, p<0.0001\right.$; $\left.\beta_{\text {young }}=0.17, F(1,1464)=45.54, p<0.0001\right)$. In sum, in line with predictions, needed support was related to more negative affect on the same day in both age groups.

\section{Balance of received and needed support}

The estimates of the multilevel models with the balance of received and needed emotional support as predictor are shown in Table 3. We expected a significant quadratic relationship between balance support and negative affect and health complaints, indicating more negative affect and more health complaints in case of over- and undersupply of support and the least negative affect and health complaints in case of balanced support. For older adults, this quadratic relationship was assumed to be less pronounced for negative affect and more pronounced for the health complaints.

\section{Health complaints as the dependent variable}

Linear balance and quadratic balance support were significant predictors of health complaints, $\beta_{\text {balance }}=-0.11, F(1,3132)=7.03$, $p=0.01 ; \beta_{\text {balance }^{2}}=0.07, F(1,3132)=11.02, p=0.001$. In addition, the interaction of quadratic balance support and age group was significant, indicating age differences in the quadratic association between younger and older adults, $\beta=-0.07, F(1,3132)=6.12$, $p=0.01$. Separate analyses for younger and older adults showed significant effects of linear and quadratic balance support only in younger adults. For them, linear and quadratic balance accounted for $4 \%$ of the within-person variance of the health complaints, $\beta_{\text {balance }}=-0.12, F(1,1463)=5.30, p=0.02 ; \beta_{\text {balance }^{2}}=0.07$, $F(1,1463)=8.08, p=0.005$. The daily relationships between balance support and health complaints for both age groups are illustrated in Fig. 2A.

\section{Negative affect as the dependent variable}

Linear and quadratic balance were significant level-one predictors, $\beta_{\text {balance }}=-0.14, F(1,3132)=72.53, p<0.0001$; $\beta_{\text {balance }^{2}}=0.05, F(1,3132)=25.68, p<0.0001$. In addition, the interactions of linear balance support and age group as well as of quadratic balance support and age group were reliable, indicating age differences in linear and quadratic relations, $\beta_{\text {balance }} \times$ age group $=0.12, F(1,3132)=24.20, p<0.0001 ; \beta_{\text {balance }^{2} \times \text { age group }}=-0.05$, $F(1,3132)=15.46, p<0.0001$. Separate analyses by age group

Table 2

Multilevel models with predictors needed or received emotional support.

\begin{tabular}{|c|c|c|c|c|c|c|c|c|}
\hline \multirow{3}{*}{$\frac{\text { Dependent variable }}{\text { Independent support variable }}$} & \multicolumn{4}{|c|}{ Health complaints } & \multicolumn{4}{|l|}{ Negative affect } \\
\hline & \multicolumn{2}{|c|}{ Needed support } & \multicolumn{2}{|c|}{ Received support } & \multicolumn{2}{|l|}{ Needed support } & \multicolumn{2}{|l|}{ Received support } \\
\hline & Estimate (SE) & $p$ & Estimate (SE) & $p$ & Estimate (SE) & $p$ & Estimate (SE) & $p$ \\
\hline \multicolumn{9}{|l|}{ Fixed effects } \\
\hline Intercept & $1.05(0.51)$ & 0.04 & $1.11(0.52)$ & 0.03 & $0.07(0.24)$ & 0.77 & $0.25(0.26)$ & 0.33 \\
\hline Linear trend & $-0.01(0.01)$ & 0.06 & $-0.01(0.01)$ & 0.06 & $-0.004(0.002)$ & 0.05 & $-0.01(0.002)$ & 0.01 \\
\hline Age group & $0.03(0.24)$ & 0.89 & $0.05(0.23)$ & 0.84 & $-0.60(0.11)$ & $<0.0001$ & $-0.63(0.12)$ & $<0.0001$ \\
\hline Support mean & $-0.03(0.13)$ & 0.81 & $-0.04(0.12)$ & 0.76 & $0.21(0.07)$ & 0.001 & $-0.02(0.06)$ & 0.70 \\
\hline Support & $0.19(0.05)$ & $<0.0001$ & $0.05(0.04)$ & 0.15 & $0.16(0.02)$ & $<0.0001$ & $-0.02(0.02)$ & 0.23 \\
\hline Age group $\times$ Support & $-0.10(0.06)$ & 0.13 & $-0.01(0.05)$ & 0.79 & $-0.13(0.02)$ & $<0.0001$ & $0.01(0.02)$ & 0.51 \\
\hline \multicolumn{9}{|l|}{ Random effects ${ }^{\mathrm{a}}$} \\
\hline Intercept & $1.87(0.26)$ & $<0.0001$ & $1.84(0.26)$ & $<0.0001$ & $0.41(0.05)$ & $<0.0001$ & $0.44(0.06)$ & $<0.0001$ \\
\hline Linear trend & $0.004(0.001)$ & $<0.0001$ & $0.004(0.001)$ & $<0.0001$ & $0.0003(0.0001)$ & $<0.0001$ & $0.0002(0.0001)$ & 0.0002 \\
\hline Support & $0.09(0.02)$ & $<0.0001$ & $0.03(0.01)$ & 0.01 & $0.01(0.003)$ & $<0.0001$ & $0.004(0.002)$ & 0.003 \\
\hline Autoregression & $0.28(0.02)$ & $<0.0001$ & $0.28(0.02)$ & $<0.0001$ & $0.18(0.02)$ & $<0.0001$ & $0.20(0.03)$ & $<0.0001$ \\
\hline Residual & $1.39(0.04)$ & & $1.45(0.05)$ & & $0.26(0.01)$ & & $0.27(0.01)$ & \\
\hline
\end{tabular}

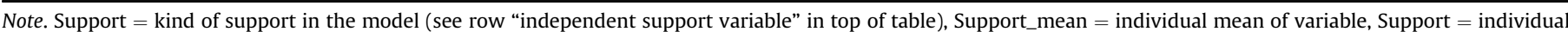

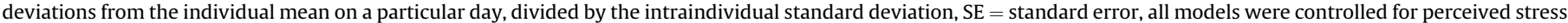
on mean level and as time varying variable.

a $p$-Values of random effects of the variables intercept, linear trend, and support are those of a $\chi^{2}$ difference test of models with and without these effects. 
Table 3

Multilevel model with the balance of received and needed support as predictor.

\begin{tabular}{|c|c|c|c|c|}
\hline \multirow{2}{*}{$\begin{array}{l}\text { Dependent variable } \\
\text { Parameter }\end{array}$} & \multicolumn{2}{|c|}{ Health complaints } & \multicolumn{2}{|l|}{ Negative affect } \\
\hline & Estimates (SE) & $p$ & Estimates (SE) & $p$ \\
\hline \multicolumn{5}{|l|}{ Fixed effects } \\
\hline Intercept & $0.93(0.51)$ & 0.07 & $0.23(0.24)$ & 0.35 \\
\hline Linear trend & $-0.01(0.01)$ & 0.03 & $-0.01(0.002)$ & 0.01 \\
\hline Age group & $0.12(0.24)$ & 0.63 & $-0.55(0.12)$ & $<0.0001$ \\
\hline Balance mean & $-0.03(0.12)$ & 0.82 & $-0.20(0.06)$ & 0.001 \\
\hline Balance & $-0.11(0.04)$ & 0.01 & $-0.14(0.02)$ & $<0.0001$ \\
\hline Balance $^{2}$ & $0.07(0.02)$ & 0.001 & $0.05(0.01)$ & $<0.0001$ \\
\hline Age group $\times$ Balance & $0.08(0.06)$ & 0.17 & $0.12(0.02)$ & $<0.0001$ \\
\hline${\text { Agegroup } \times \text { Balance }^{2}}^{2}$ & $-0.07(0.03)$ & 0.01 & $-0.05(0.01)$ & $<0.0001$ \\
\hline \multicolumn{5}{|l|}{ Random effects ${ }^{\mathrm{a}}$} \\
\hline Intercept & $1.89(0.27)$ & $<0.0001$ & $0.43(0.06)$ & $<0.0001$ \\
\hline Linear trend & $0.004(0.001)$ & $<0.0001$ & $0.0003(0.0001)$ & 0.0001 \\
\hline Balance & $0.05(0.01)$ & $<0.0001$ & $0.01(0.002)$ & $<0.0001$ \\
\hline Balance $^{2}$ & $0.001(0.004)$ & $<0.0001$ & $0.002(0.001)$ & $<0.0001$ \\
\hline Autoregression & $0.29(0.02)$ & $<0.0001$ & $0.19(0.03)$ & $<0.0001$ \\
\hline Residual & $1.44(0.05)$ & & $0.25(0.01)$ & \\
\hline
\end{tabular}

Note. Balance $=$ received - needed support on a particular day (individual deviations from the individual mean on a particular day, divided by the intraindividual standard deviation), Balance_mean = individual mean of variable, SE = standard error, all models were controlled for perceived stress on mean level and as time varying variable.

a $p$-values of random effects of the variables intercept, linear trend, and Balance, and Balance ${ }^{2}$ are those of a likelihood ratio test of models with and without these effects.

showed a significant effect of linear balance support for older adults, $\beta_{\text {balance }}=-0.04, F(1,1668)=15.53, p<0.0001$, and significant effects of linear and quadratic balance support for younger adults, $\beta_{\text {balance }}=-0.16, F(1,1463)=45.87, p<0.0001 ; \beta_{\text {balance }^{2}}=0.05$, $F(1,1463)=13.05, p=0.0003$. For older adults, balance support accounted for $2 \%$ of the within-person variability of NA. For the younger adults, linear and quadratic balance support taken together accounted for $13 \%$ of the within-person variance of negative affect. The daily relationships between balance emotional support and negative affect for both age groups are illustrated in Fig. 2B.

\section{Discussion}

This study investigated the links of received emotional support, needed emotional support, and the balance between the two, respectively, to health complaints as well as negative affect. Associations were investigated as they occur within individuals on a day-to-day basis. Younger and older adults were compared. Needed support was related to more health complaints and more negative affect on the same day, while received support was not. The balance between needed and received support showed the expected quadratic association to negative affect and health complaints, but only among younger adults. In the older adults, a linear association between support balance and negative affect was observed, with negative affect being lower on days with more support.

\section{Needed support}

As expected, on days participants needed more support, they reported more health complaints and more negative affect. For this finding, both directions of influence seem plausible. First, individuals may feel in greater need of support on days with lower physical and emotional well-being. Second, the need for emotional support may lower well-being and exacerbate the experience of health symptoms. Remarkably, these findings were independent from the occurrence of stress on a daily basis and in general, meaning that needing support subsumes more than just the stress experienced by a person. For health complaints, the observed associations did not differ between the two age groups. For negative affect, the association was stronger for younger adults than for older adults. Apparently, younger adults were more sensitive to daily variations in need for support. Potentially, habituation to the need of support over the life course may play a role for older adults. This is also an often discussed explanation for findings of reduced emotional reactivity in older adults (Brose et al., 2011). Regarding the reverse directionality, younger adults may need more support when feeling bad, whereas older adults may use other coping strategies in cases of negative mood. Thus, they may use strategies such as internal down-regulation of negative affect, revaluation of events or distraction rather than social support to enhance their mood (cf. Blanchard-Fields, 2007).

\section{Received support}

Received emotional support was not reliably related to reported health complaints or negative affect on the same day. This result is inconsistent with previous research showing that received support is associated with worse outcomes on the same day (e.g., Gleason et al., 2008; Maisel \& Gable, 2009). However, the studies investigating daily relationships so far included received support within couples. In our study, the source of support was not specified. Perhaps, receiving support from less close social partners is less likely to induce negative feelings such as guilt. Future research should investigate whether different kinds and sources of support are differentially related to affect and self-reported health.

\section{The balance of received and needed support}

The balance between received and needed support did show the expected quadratic relationship with health complaints and negative affect in younger adults. In older adults, a small but reliable linear relationship between balance support and negative affect
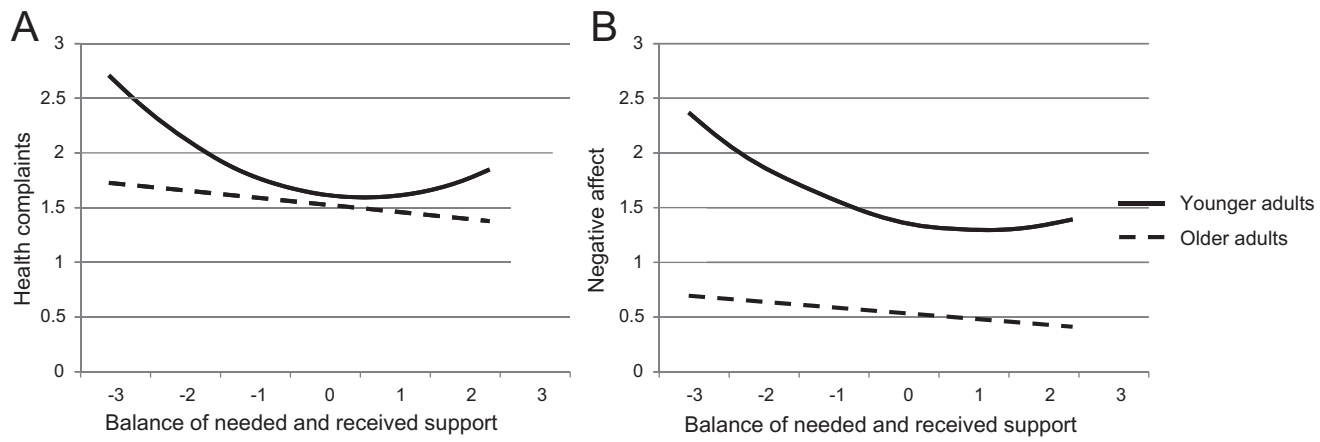

Fig. 2. Daily relationship between balance support and health complaints (A) and negative affect (B) in both age groups. 
was found, indicating that the more support is received the better. In accordance with socio-emotional selectivity theory (cf., Carstensen et al., 2003), older adults seem to be able to make use of an oversupply of support in favor of their well-being. In line with this interpretation, we also replicated a common finding that older adults reported less negative affect (cf., Charles, Reynolds, \& Gatz, 2001). It is often discussed that older adults do not need reciprocity in their relationships as much as younger adults, because they know how much support they already gave to their social partners across their whole life (cf. convoy theory; Antonucci \& Akiyama, 1987). Therefore, an oversupply of support may result less often in feelings of guilt among older adults. Contrary to our predictions, older adults did not report more health complaints on days with too little or too much emotional support. This may mean that they do not need the right amount of support to deal with their health complaints, because the complaints may be a chronic condition to which they have adapted or because they use other coping resources to deal with their daily problems. In line with this, the results of less needed but an equal amount of received support in older compared to younger adults (see Table 1) may underline the often made assumption of older adult's better competency to cope with emotional and interpersonal problems (Blanchard-Fields, 2007).

In sum, these results can be interpreted as good news - older adults are not dependent on a good fit between their need for support and actual help received on that day. At least in daily relationships, they do not seem to be sensitive to under- or oversupply of support in terms of health complaints or negative affect. Older adults also varied less in negative affect and health complaints from day to day than younger adults. This may suggest they are more stable in their emotional and physical experiences (Röcke, Li, \& Smith, 2009; Wolff et al., 2012) and thereby less affected by unbalanced support. Additionally, emotional close social relationships are stable and high in quality up into old ages and their reliability may even increase with age (e.g., Fingerman \& Charles, 2010; Lang, 2000; Rook, Mavandadi, Sorkin, \& Zettel, 2007). Thus, if needed support is not received today older adults know it will be available in the future. Also, older adults are often more satisfied with their social relationships and therefore may have a less pronounced reaction to conflict that may result from an oversupply of support (cf., Birditt \& Fingerman, 2003; Birditt, Fingerman, \& Almeida, 2005; Luong et al., 2011). Finally, we cannot exclude that older adults' lower sensitivity to unbalanced support reflects age-related decrements in individuals' ability to recognize when they actually are in need of help. Such decrements may be present in some but not all older adults (cf. Lang, Rieckmann, \& Baltes, 2002), and may leave these older individuals without necessary help in situations in which they need it because actual needs are less likely to be communicated.

In younger adults, we could show the expected quadratic relationship for emotional and physical well-being (see Fig. 2). As in the case of the association between needed support and negative affect, they apparently were more sensitive to under- and oversupply of support than older adults. Perhaps, older adults habituated to needing and receiving support throughout their life and, thus, it affects them less than younger adults. Support oversupply may be a threat to younger adults' developmental goals of autonomy and thereby constitute a stressor in itself (Havighurst, 1948). As shown in Fig. 2, the lowest levels of negative affect or health complaints were reported on days with some oversupply of support. Maybe receiving too much support does not necessarily stress its recipient, but can also be a signal of being loved and cared for. Future research needs to follow up on these ideas. For instance, it seems worth investigating whether the beneficial balance point between needed and received support depends on the kinds of situations in which younger and older adults need support.

\section{Limitations and future directions}

As shown in the comparison with the SOEP sample, the older participants were selective in terms of subjective health which may have led to an underestimation of the results concerning the health complaints. However, a more objective parameter (doctor visits) did not show this selection bias. Nevertheless, future research should focus on the balance of support and health outcomes in frailer samples of older adults. Additional selection effects may have occurred because study participation was very time consuming and because of the high study incentives which may have attracted individuals from the lower income spectrum.

Further, we cannot rule out that the results of this study are due to cohort effects. Being old today comprises very different experiences than being old in past generations and the life history of the older adults may play an important role, especially concerning social relationships and coping with health problems. For example, social networks have different meanings to younger and older generations (cf. Shearer \& Fleury, 2006). Therefore, our results concerning the age differences should be regarded with caution. Future research should investigate the social support - health/ well-being relationship longitudinally to disentangle aging and cohort effects.

Future studies would benefit a lot from including information on the source of support as this may also have age-differential effects (e.g., Fiori, Smith, \& Antonucci, 2007). Relatedly, the predictors generally accounted for larger portions of variance in negative affect than in health complaints. This may be due to the fact that emotional support was used as a predictor, which is more likely to relate to affect than to health. Maybe for other, especially healthrelated, kinds of support (e.g., autonomy support) the effect on health outcomes is stronger. Magret M. Baltes (1995) pointed to the importance of the support of independence in older adults. A balance of autonomy support may have shown different results. Also, support oversupply may evoke different emotional reactions than support undersupply. It is conceivable that an undersupply of support induces feelings of loneliness and helplessness, while an oversupply of support provokes emotions like anger and irritability. Future research should investigate effects of the balance of received and needed support of different kinds on various health and wellbeing outcomes in order to differentiate effects of under- and oversupply of support.

The amount of needed and received support was self-reported in this study and reflects the individual perception of what is needed rather than what a person actually needs. Not everyone might be aware of how much emotional support he or she needs. Additionally, as undersupply of support may also result from ineffective strategies to ask for support that is needed, it would be intriguing to find out about interindividual differences in how effectively optimal levels of support are achieved. The report of daily health complaints over only 20 days is of course not representative of the daily life of the participants. It may just represent changes in perceptions or a reflection of an acute illness. Still, if our attention towards health complaints (i.e., suffering from them) is attenuated by social support on a daily basis, this is relevant for illness perceptions and can be an important coping mechanism with diseases.

An important question that can be addressed in future studies is the directionality of the observed associations. Event-sampling techniques in which support is measured prior and after changes in well-being and health would be ideally suited to capture directionality. Moreover, it seems promising to investigate additional 
age-specific coping strategies to enhance subjective symptom reporting in, for example, rehabilitation programs. For younger adults, our findings suggest that the provision of emotional support as such may not be enough. Rather, it may be necessary to ascertain the amount of needed support to achieve beneficial effects of received support.

Finally, further research on the underlying mechanisms that explain the social support-health relationship is needed (cf. Uchino, Bowen, Carlisle, \& Birmingham, 2012). The short-term effects of a balance of needed and received support are a first step to further understand daily network interactions. Still, future research should clarify whether these positive effects are part of mediation processes that lead to better health or well-being in the long run.

\section{Conclusion}

This study investigated the daily associations of needed support, received support, and the balance between needed and received support to emotional well-being and health complaints. The need for support was related to more health complaints and negative affect on the same day, while received support was not. These effects were reliable controlling for the experienced stress on that day. The association between needed support and negative affect was stronger in younger adults than in older adults. Support balance showed the expected quadratic relationship with negative affect and health complaints in younger adults. Younger adults seem to react more sensitively to over- and undersupply of support. Instead, older adults seem to profit from support when they need it irrespective of whether it exceeds current demands. This study helps to explain earlier results documenting negative associations between received support on health and well-being. It was receiving support that does not match the needs of the recipient rather than receiving support per se that was associated with unfortunate outcomes in younger adults. The current study underscores the need to consider the balance between received and needed support to further our understanding of the relation between support and various aspects of well-being across the adult lifespan.

\section{Acknowledgements}

The authors thank Martin Lövdén, Colin Bauer, Gabriele Faust, Katja Müller-Helle, Birgit Heim, Annette Rentz-Lühning, and a team of highly committed student research assistants for their help in conducting the Study, Julia Delius for editorial assistance, and Clemens Tesch-Römer and Verena Klusmann for helpful discussions on this manuscript. The COGITO Study was supported by the Max Planck Society, including a grant from the innovation fund of the Max Planck Society (M.FE.A.BILD0005); the Alexander von Humboldt Foundation's Sofja Kovalevskaja Award (to Martin Lövdén), which is funded by the German Federal Ministry for Education and Research (BMBF); the German Research Foundation (DFG; KFG 163); and the German Federal Ministry for Education and Research (BMBF; CAI).

\section{References}

Aldwin, C. M., Park, C. L., \& Spiro, I. A. (2007). Health psychology and aging: an introduction. In C. M. Aldwin, C. L. Park, \& A. Spiro, III (Eds.), Handbook of health psychology and aging (pp. 3-8). New York: Guilford Press.

Almeida, D. M., Wethington, E., \& Kessler, R. C. (2002). The daily inventory of stressful events: an interview-based approach for measuring daily stressors. Assessment, 9(1), 41-55.

Antonucci, T. C., \& Akiyama, H. (1987). Social networks in adult life and a preliminary examination of the convoy model. Journal of Gerontology, 42(5), 519-527.
Antonucci, T. C., \& Jackson, J. S. (1987). Social support, interpersonal efficacy, and health: a life course perspective. In L. L. Carstensen, \& B. A. Edelstein (Eds.) Handbook of clinical gerontology (pp. 291-311). New York: Pergamon Press.

Atienza, A. A., Collins, R., \& King, A. C. (2001). The mediating effects of situational control on social support and mood following a stressor: a prospective study of dementia caregivers in their natural environments. The Journals of Gerontology, Series B: Psychological Sciences and Social Sciences, 56(3), S129-S139.

Baltes, P. B. (1987). Theoretical propositions of life-span developmental psychology: on the dynamics between growth and decline. Developmental Psychology, 23, $611-626$.

Baltes, M. M. (1995). Dependency in old age: gains and losses. Current Directions in Psychological Science, 4(1), 14-19.

Birditt, K. S., \& Fingerman, K. L. (2003). Age and gender differences in adults' descriptions of emotional reactions to interpersonal problems. The Journals of Gerontology, Series B: Psychological Sciences and Social Sciences, 58(4), P237P245.

Birditt, K. S., Fingerman, K. L., \& Almeida, D. M. (2005). Age differences in exposure and reactions to interpersonal tensions: a daily diary study. Psychology and Aging, 20(2), 330-340.

Blanchard-Fields, F. (2007). Everyday problem solving and emotion: an adult developmental perspective. Current Directions in Psychological Science, 16(1), 26-31.

Bolger, N., \& Amarel, D. (2007). Effects of social support visibility on adjustment to stress: experimental evidence. Journal of Personality and Social Psychology, 92(3), 458-475.

Bolger, N., Zuckerman, A., \& Kessler, R. C. (2000). Invisible support and adjustment to stress. Journal of Personality and Social Psychology, 79(6), 953-961.

Brähler, E., Hinz, A., \& Scheer, J. W. (2008). Der Gießener Beschwerdebogen [The Giessen Subjective Complaints list]. Bern: Huber.

Brock, R., \& Lawrence, E. (2009). Too much of a good thing: underprovision versus overprovision of partner support. Journal of Family Psychology, 23(2), 181-192.

Brose, A., Schmiedek, F., Lövdén, M., Molenaar, P. C. M., \& Lindenberger, U. (2010) Adult age differences in covariation of motivation and working memory performance: contrasting between-person and within-person findings. Research in Human Development, 7(1), 61-78.

Brose, A., Schmiedek, F., Lövdén, M., \& Lindenberger, U. (2011). Normal aging dampens the link between intrusive thoughts and negative affect in reaction to daily stressors. Psychology and Aging, 26(2), 488-502.

Carstensen, L. L. (1995). Evidence for a life-span theory of socioemotional selectivity. Current Directions in Psychological Science, 4(5), 151-156.

Carstensen, L. L., Fung, H. H., \& Charles, S. T. (2003). Socioemotional selectivity theory and the regulation of emotion in the second half of life. Motivation and Emotion, 27(2), 103-123.

Charles, S. T., Reynolds, C. A., \& Gatz, M. (2001). Age-related differences and change in positive and negative affect over 23 years. Journal of Personality and Social Psychology, 80(1), 136-151.

Cohen, S. (1988). Psychosocial models of the role of social support in the etiology of physical disease. Health Psychology, 7(3), 269-297.

Cohen, S., Kamarck, T., \& Mermelstein, R. (1983). A global measure of perceived stress. Journal of Health and Social Behavior, 24(4), 385-396.

Cutrona, C. E. (1990). Stress and social support: in search of optimal matching. Journal of Social and Clinical Psychology, 9(1), 3-14.

Fingerman, K. L., \& Charles, S. T. (2010). It takes two to tango: why older people have the best relationships. Current Directions in Psychological Science, 19(3), 172-176.

Fiori, K. L., Smith, J., \& Antonucci, T. C. (2007). Social network types among older adults: a multidimensional approach. The Journals of Gerontology, Series B: Psychological Sciences and Social Sciences, 62B(6), P322-P330.

Gleason, M. E. J., Bolger, N., Iida, M., \& Shrout, P. E. (2008). Receiving support as a mixed blessing: evidence for dual effects of support on psychological outcomes. Journal of Personality and Social Psychology, 94(5), 824-838.

Gleason, M. E. J., Iida, M., Bolger, N., \& Shrout, P. E. (2003). Daily supportive equity in close relationships. Personality and Social Psychology Bulletin, 29(8), 1036-1045.

Haber, M. G., Cohen, J. L., Lucas, T., \& Baltes, B. B. (2007). The relationship between self-reported received and perceived social support: a meta-analytic review. American Journal of Community Psychology, 39(1-2), 133-144.

Havighurst, J. R. (1948). Developmental tasks and education. Chicago: University of Chicago Press.

House, J. S., Landis, K. R., \& Umberson, D. (1988). Social relationships and health. Science, 241(4865), 540-545.

House, J. S., Landis, K. R., \& Umberson, D. (2003). Social relationships and health. In P. Salovey, \& A. J. Rothman (Eds.), Social psychology of health (pp. 218-226). New York: Psychology Press.

Jou, Y. H., \& Fukada, H. (2002). Stress, health, and reciprocity and sufficiency of social support: the case of university students in Japan. Journal of Social Psychology, 142(3), 353-370.

Jung, J. (1997). Balance and source of social support in relation to well-being. Journal of General Psychology, 124(1), 77-90.

Karademas, E. C. (2006). Self-efficacy, social support and well-being: the mediating role of optimism. Personality and Individual Differences, 40(6), 1281-1290.

Krause, N. (1997). Received support, anticipated support, social class, and mortality. Research on Aging, 19(4), 387-422.

Lang, F. R. (2000). Endings and continuity of social relationships: maximizing intrinsic benefits within personal networks when feeling near to death. Journal of Social and Personal Relationships, 17(2), 155-182. 
Lang, F. R., Featherman, D. L., \& Nesselroade, J. R. (1997). Social self-efficacy and short-term variability in social relationships: the MacArthur successful aging studies. Psychology and Aging, 12(4), 657-666.

Lang, F. R., Rieckmann, N., \& Baltes, M. M. (2002). Adapting to aging losses: do resources facilitate strategies of selection, compensation, and optimization in everyday functioning? The Journals of Gerontology, Series B: Psychological Sciences and Social Sciences, 57B(6), 501-509.

Luong, G., Charles, S. T., \& Fingerman, K. L. (2011). Better with age: social relationships across adulthood. Journal of Social and Personal Relationships, 28(1) 9-23.

Maisel, N. C., \& Gable, S. L. (2009). The paradox of received social support: the importance of responsiveness. Psychological Science, 20(8), 928-932.

Murrell, S. A., Norris, F. H., \& Chipley, Q. T. (1992). Functional versus structural socia support, desirable events, and positive affect in older adults. Psychology and Aging, 7(4), 562-570.

Reinhardt, J. P., Boerner, K., \& Horowitz, A. (2006). Good to have but not to use: differential impact of perceived and received support on well-being. Journal of Social and Personal Relationships, 23(1), 117-129.

Reynolds, J. S., \& Perrin, N. A. (2004). Mismatches in social support and psychosocial adjustment to breast cancer. Health Psychology, 23(4), 425-430.

Röcke, C., Li, S.-C., \& Smith, J. (2009). Intraindividual variability in positive and negative affect over 45 days: do older adults fluctuate less than young adults? Psychology and Aging, 24(4), 863-878.

Rook, K. S., Mavandadi, S., Sorkin, D. H., \& Zettel, L. A. (2007). Optimizing social relationships as a resource for health and well-being in later life. In C. M. Aldwin, C. L. Park, \& A. Spiro, III (Eds.), Handbook of health psychology and aging (pp. 267-285). London: Guilford Press.

Schmiedek, F., Bauer, C., Lövdén, M., Brose, A., \& Lindenberger, U. (2010). Cognitive enrichment in old age: Web-based training programs. Journal of Gerontopsychology and Geriatric Psychiatry, 23(2), 59-67.

Schmiedek, F., Lövdén, M., \& Lindenberger, U. (2009). On the relation of mean reaction time and intraindividual reaction time variability. Psychology and Aging, 24(4), 841-857.

Schmiedek, F., Lövdén, M., \& Lindenberger, U. (2010b). Hundred days of cognitive training enhance broad cognitive abilities in adulthood: findings from the COGITO study. Frontiers in Aging Neuroscience, 2(1), 1-10.

Seeman, T. (2001). How do others get under our skin? In C. D. Ryff, \& B. H. Singe (Eds.), Emotion, social relationships, and health (pp. 189-220) New York: Oxford University Press.
Seidman, G., Shrout, P. E., \& Bolger, N. (2006). Why is enacted social support associated with increased distress? Using simulation to test two possible sources of spuriousness. Personality and Social Psychology Bulletin, 32(1), 52-65.

Shearer, N., \& Fleury, J. (2006). Social support promoting health in older women. Journal of Women E Aging, 18(4), 3-17.

Shrout, P. E., Herman, C. M., \& Bolger, N. (2006). The costs and benefits of practical and emotional support on adjustment: a daily diary study of couples experiencing acute stress. Personal Relationships, 13(1), 115-134.

Siewert, K., Antoniw, K., Kubiak, T. \& Weber, H. (2011). The more the better? the relationship between mismatches in social support and subjective well-being in daily life. Journal of Health Psychology, 16(4), 621-631.

Smith, J., \& Goodnow, J. J. (1999). Unasked-for support and unsolicited advice: age and the quality of social experience. Psychology and Aging, 14(1), 108-121.

Uchino, B. N. (2006). Social support and health: a review of physiological processes potentially underlying links to disease outcomes. Journal of Behavioral Medicine, 29(4), 377-387.

Uchino, B. N. (2009). Understanding the links between social support and physical health: a life-span perspective with emphasis on the separability of perceived and received support. Perspectives on Psychological Science, 4(3), 236-255.

Uchino, B. N., Bowen, K., Carlisle, M., \& Birmingham, W. (2012). Psychological pathways linking social support to health outcomes: a visit with the "ghosts" of research past, present, and future. Social Science \& Medicine, 74(7), 949-957.

Uchino, B. N., Cacioppo, J. T. \& Kiecolt-Glaser, J. K. (1996). The relationship between social support and physiological processes: a review with emphasis on underlying mechanisms and implications for health. Psychological Bulletin, 119(3), 488-531.

Väänänen, A., Buunk, B. P., Kivimaki, M., Pentti, J., \& Vahtera, J. (2005). When it is better to give than to receive: long-term health effects of perceived reciprocity in support exchange. Journal of Personality and Social Psychology, 89(2), 176-193.

Wagner, G. G., Frick, J. R. \& Schupp, J. (2007). The German socio-economic panel study (SOEP): scope, evolution and enhancements. Journal of Applied Social Sciences, 127(1), 139-169.

Watson, D., Clark, L. A., \& Tellegen, A. (1988). Development and validation of brief measures of positive and negative affect: the PANAS Scales. Journal of Personality and Social Psychology, 54, 1063-1070.

Wolff, J. K., Brose, A., Lövdén, M., Tesch-Römer, C., Lindenberger, U., \& Schmiedek, F. (2012). Health is health is health? Age differences in intraindividual variability and within-person versus between-person factor structures of self-reported physical symptoms. Psychology and Aging, 27(4), 881-891. 